\title{
Multi-criteria Optimization in Solving the Problem of Expanding Production Capacity of an Enterprise as a Method of Modeling Strategic Directions for the Development of Production Systems
}

\author{
Olga Shatalova ${ }^{1, *}$, Ekaterina Kasatkina ${ }^{2}$, and Valery Larionov ${ }^{3}$ \\ ${ }^{1}$ Udmurt branch of Institute of Economics of Ural Branch of Russian Academy of Science, 4 \\ Lomonosova str., Izhevsk, Russia, 426004 \\ ${ }^{2}$ Kalashnikov Izhevsk State Technical University, 7 Studencheskaya str., Izhevsk, Russia, 426069 \\ ${ }^{3}$ Bauman Moscow State Technical University, 5/1, 2th Baumanskaya str., Moscow, Russia, 105005
}

\begin{abstract}
Managing production capacity of industrial enterprises is an important element of the strategy for the development of production systems. The relevance of effective decision support methods in managing production capacity especially increases in the current conditions of a longterm decline in investment activity of Russian industrial enterprises and, as a result, a shortage of modern high-tech equipment, which becomes a significant limiting factor in the development of territorially oriented production systems. The article presents approaches to mathematical modeling and optimization of production capacity of industrial enterprises in solving the problem of its expansion under given budget constraints. The proposed mathematical model includes key parameters of the technical and economic planning of production capacity of a technological site and serves as a tool to justify the choice of an acceptable method for its expansion. The multicriteria optimization methods used in the model serve in this case as a means of formalized description and reaching a reasonable compromise based on the required values of the target parameter and budget constraints, as well as preferences of the decision maker. The article contains an example of the numerical implementation of the developed model in the management of production capacity of a machining site; the example illustrates practical applicability of this model and the result of multicriteria optimization from the standpoint of restrained pessimism of the decision maker.
\end{abstract}

\section{Introduction}

The low investment activity of Russian industrial enterprises, noted by many researchers and confirmed by the data of state statistics, determines high significance of the problem of shortage of modern high-tech production facilities. This determines the relevance of

\footnotetext{
*Corresponding author: oshatalova@mail.ru
} 
effective methods for supporting management decisions in the development and modeling of strategic directions for the development of production systems.

The level of production capacity of an industrial enterprise is an important technical and economic parameter that determines not only its operational results, but also strategic opportunities and threats. The PC level is considered a factor of effective market competition [1,2,3, etc.]. At the same time, in the conditions of PC deficit, effective tactical ways to overcome it have developed, such as prompt redistribution of the production program, cooperation with subcontractors, regulation of equipment use modes, etc. $[4,5,6$ and others]. To implement such methods, there are adequate scientific and practical methods for supporting decision-making in PC management.

In the management of production capacity, it is customary to distinguish three levels strategic, tactical, operational [7]. Strategic decisions in PC management are based on the content of the enterprise's business strategy, including, inter alia, long-term forecasts of demand and the type of strategic behavior of the enterprise, and form the upper limit on the volume of output and the lower limit on the production cost; in this case, the substantiation of the size of PC stock becomes a fundamentally significant task [8]. Tactical level decisions in PC management are aimed, as a rule, at ensuring current orders and/or medium-term production plans based on an assessment of the needs of the respective product markets. The main management tasks in this case are to achieve the specified output volumes with a balanced load of fixed assets and, if necessary, to develop solutions to eliminate the so-called 'bottlenecks' [9] - PC deficit for certain groups of equipment. The PC operational management solves the tasks of fulfilling short-term planned tasks.

For each level of PC management, different approaches and decision support methods are applicable. In the system of PC strategic management, for the formation of main parameters, as a rule, heuristic methods of analysis and forecasting are used, which are aimed at compensating information deficiency in conditions of non-stochastic uncertainty due to expert knowledge of the decision maker about the system and its environment. In the operational management of PC, mainly scheduling and dispatching methods are used. In the tactical management of PC, a wide arsenal of methods of technical and economic calculations has been formed, which make it possible to make a deterministic assessment of the stock or shortage of PC by groups of leading equipment for implementation of a production program for the medium-term planning period. This calculation serves as basis for the development of management decisions for PC optimization in the context of groups of leading equipment. In this case, managerial decisions are analyzed according to several criteria, which requires adequate methods to make a reasonable choice from a discrete set of feasible alternatives based on the specified constraints and taking into account preferences of the decision maker; such a choice implies, as a rule, a reasonable compromise, which can be formalized, described and solved by the methods of multicriteria optimization (MCO).

The use of multicriteria optimization approaches in solving problems of managing organizational systems presupposes a reasonable and correct application of mathematical methods for modeling objective functions, normalization, convolution of particular criteria, etc.

Equally important is correct formulation of the problem and its corresponding presentation in the form of target functions and specified constraints; the correct formulation of the problem is based on the content of the subject area of the study.

The article presents the results of using MCO methods in managing production capacity at the level of a technological section of machining. With regard to the specifics of this control object, a general formulation of the problem was drawn up to solve the problem of PC deficit, in accordance with which the objective function of particular criteria was 
constructed and the MCO was compiled on basis of various methods for obtaining a generalized criterion.

\section{Methodological foundations of the research}

The study used two groups of methodological foundations: general methods of deterministic PC calculations and methods of multi-criteria optimization.

Calculation of PC of technological areas of machining is reduced to assessing the level of conformity of available and required PC in the context of each group of leading equipment; on basis of such an assessment, the final value of PC for the site is established according to the minimum value of the ratio of the available and required PC. The calculation is carried out by deterministic methods and includes the following parameters: planned production volume, time norms, amount of equipment, machine time fund; it is assumed that in order to assess alternative options for solving the problem of PC deficit, a series of appropriate calculations should be carried out in accordance with the general traditional methodology $[10,11$, etc. $]$.

The use of MCO methods for assessing alternative options for expanding PC of the site enables one to clarify and systematize the content of the problem itself, as well as justify the choice of an acceptable alternative.

In general, the procedure of multicriteria optimization involves formalization of the problem through construction of a mathematical model of the object under study and its subsequent optimization, aimed at choosing the best solution [12,13]. An important question in this case is the choice of the correct method of criteria convolution. Criteria convolution forms a scalar performance indicator based on a vector of partial criteria. As part of the research task, the methods of convolution were considered, corresponding to the decision maker's position on 'restrained pessimism'. Substantive heterogeneity (incomparability) of particular criteria is compensated by normalizing their numerical values by linear calculation of membership to the maximum value.

\section{Statement of the problem of expanding production capacity of an enterprise}

The general formulation of the problem of expanding production capacity of an enterprise in solving the problem of PC deficit is described by the following basic provisions:

- the object of research is a production site, considered as a system of class $S_{0}$, i.e. a singlepurpose system [14], for which the content and admissible values of the goal, as well as budget constraints, are set on the part of the senior system (metasystem);

- the target result of the system under study is the level of compliance of production capacity of the site with the required values;

- the assessment of alternatives is carried out from the standpoint of decision makers about 'restrained pessimism';

- alternative options for solving the problem of PC shortage include organizational and technical measures associated with a one-time investment in the purchase of additional equipment (in this case, the assumption is made in the problem that the new and existing equipment are completely identical) and/or in the modernization of existing equipment aimed at reducing the norms of machine time;

- it is required to determine the composition of active funds that ensures the achievement of the required level of the target result under the established restrictions;

- the decision-making criterion is the efficiency indicator, which represents the result of the convolution of particular criteria: maximization of the target parameter (PC of the site) and 
minimization of one-time investments associated with introduction of additional units of equipment and modernization of existing equipment.

The statement of the problem of a systemic study of PC deficiency can be represented by the following mathematical model:

$$
\begin{gathered}
f_{1}=C(\mathbf{u})=C k(\mathbf{u})+C m(\mathbf{u}) \rightarrow \min , \\
f_{2}=\Delta P C(\mathbf{u})=\min \left\{P C_{i}(\mathbf{u})\right\}-P C^{0} \rightarrow \max , \\
P C_{i}(\mathbf{u})=F\left\{k_{\mathrm{i}}+\left[C k_{i}(\mathbf{u}) / a_{i}\right]\right\} /\left\{N_{i}\left(1-b_{\mathrm{i}}\right)\left[C m_{i}(\mathbf{u}) / c_{i}\right]\right\}, \\
C k(\mathbf{u})=\sum_{i} C k_{i}(\mathbf{u}), \\
C m(\mathbf{u})=\sum_{i} C m_{i}(\mathbf{u}), \\
C k_{\text {min }} \leq C k(\mathbf{u}) \leq C k_{\max }, \\
C m_{\min } \leq C m(\mathbf{u}) \leq C m_{\max },
\end{gathered}
$$

where $\mathbf{u}=\left(u_{1}, u_{2}\right)$ - management strategy $\left(u_{1}-\right.$ capital investments $(\mathrm{CI})$ in new equipment; $u_{2}$ - capital investments in modernization of existing equipment);

$P C^{0}$ - initial value of production capacity of the site;

$P C_{i}(\mathbf{u})$ - the value of production capacity of the site for strategy $\mathbf{u}$ and the $\mathrm{i}$-th type of technological operation, $i=\{1,2,3\}$;

$C k$ - the amount of one-time expenses for CI in new equipment, $C k \in[500 ; 1000]$ in increments of $\triangle C k=500$;

$\mathrm{Cm}$ - the amount of one-time expenses for $\mathrm{CI}$ in modernization of existing equipment, $\mathrm{Cm} \mathrm{\epsilon}$ $[0 ; 300]$ in increments of $\Delta C m=100$;

$F$ - machine time fund, $F=167$;

$k_{\mathrm{i}}$ - number of units of installed equipment, $\mathbf{k}=\left(\begin{array}{lll}3 & 3 & 2\end{array}\right)^{\mathrm{T}}$;

$a_{\mathrm{i}}-$ unit price of new equipment, $a_{i}=500$;

$N_{i}$ - the cost of machine time for the i-th technological operation for the production of a production program, $\mathbf{N}=\left(\begin{array}{lll}466 & 341 & 495\end{array}\right)^{\mathrm{T}}$;

$b_{\mathrm{i}}$ - the estimated value of reduction in the standard of machine time during modernization of a piece of equipment, $b_{\mathrm{i}}=0.1$;

$c_{\mathrm{i}}-$ the cost of modernization a piece of equipment, $c_{\mathrm{i}}=100$.

\section{Solving the problem of expanding production capacity of an enterprise}

A discrete set of alternatives $\mathbf{u}$ was formed to solve the problem of PC deficit, since the construction of a continuous set of alternatives is impracticable in view of the presence of the function [.] with respect to parameters $C k_{i}(\mathbf{u})$ and $C m_{i}(\mathbf{u})$.

Criterion space $R^{\mathrm{m}}$ is formed in accordance with the specified objective functions (1) and (2) and is a two-dimensional vector space of estimates by criteria $f_{1}$ and $f_{2}$. The numerical values of these criteria and a graphical representation of the criteria space are shown in Table 1 and Figure 1. 
Table 1. Numerical characteristics of the criteria space.

\begin{tabular}{|c|c|c|c|c|c|c|c|}
\hline $\begin{array}{c}\text { Space / } \\
\text { criterion }\end{array}$ & Designation & $\mathbf{u}_{\mathbf{1}}$ & $\mathbf{u}_{\mathbf{2}}$ & $\mathbf{u}_{\mathbf{3}}$ & $\mathbf{u}_{\mathbf{4}}$ & $\mathbf{u}_{\mathbf{5}}$ & $\mathbf{u}_{\mathbf{6}}$ \\
\hline $\begin{array}{c}\text { Parameter } \\
\text { space }\end{array}$ & $\mathrm{D}(\mathbf{u})$ & $(500 ; 0)$ & $(500 ; 300)$ & $(1000 ; 300)$ & $(1000 ; 0)$ & $(0 ; 300)$ & $(500 ; 100)$ \\
\hline Criteria space: & & & & & & & \\
\hline $\begin{array}{c}- \text { criterion } \\
C(\mathbf{u})\end{array}$ & $f_{1}$ & 500 & 800 & 1300 & 1000 & 300 & 600 \\
\hline $\begin{array}{c}- \text { criterion } \\
\triangle P C(\mathbf{u})\end{array}$ & $f_{2}$ & 33.7 & 51.9 & 66.8 & 39.9 & 28.9 & 39.9 \\
\hline
\end{tabular}

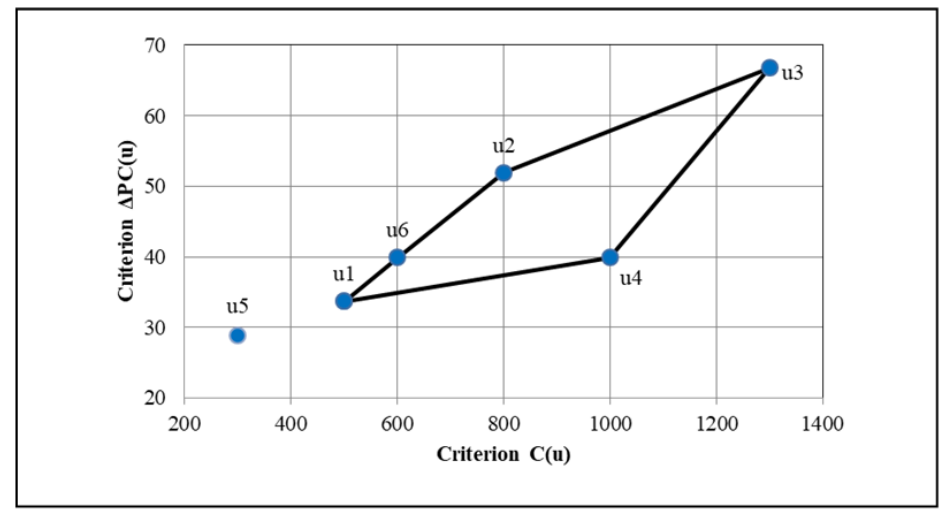

Fig. 1. Criteria space.

The Pareto-optimal set of solutions is given by two-dimensional vectors $\mathbf{u}_{1}, \mathbf{u}_{2}, \mathbf{u}_{3}, \mathbf{u}_{6}$, each of which represents the corresponding strategy. Solution $\mathbf{u}_{4}$ is non-dominant with respect to solutions $\mathbf{u}_{1}, \mathbf{u}_{2}, \mathbf{u}_{3}, \mathbf{u}_{6}$. Solution $\mathbf{u}_{5}$ is outside the set of selectable solutions.

To solve the problem of choosing the optimal strategy, MCO methods were used according to generalized criteria, corresponding to the decision maker's position on 'restrained pessimism'.

The solution to the multicriteria optimization problem was carried out according to normalized criteria $\lambda$ and $\lambda 2$ :

$$
\begin{aligned}
& \lambda_{1}=\left(f_{1}^{\text {max }}-f_{1}\right) /\left(f_{1}^{\text {max }}-f_{1}^{\text {min }}\right) \rightarrow \max , \\
& \lambda_{2}=\left(f_{2}-f_{2}^{\text {min }}\right) /\left(f_{2}^{\text {max }}-f_{2}{ }^{\text {min }}\right) \rightarrow \max ,
\end{aligned}
$$

The problem of choosing the best among Pareto-optimal solutions $\left\{\mathbf{u}_{1}, \mathbf{u}_{2}, \mathbf{u}_{3}, \mathbf{u}_{6}\right\}$ is realized using the methods of generalized maximin criterion (Wald), generalized minimax regret (Savage), and pessimism-optimism criterion (Hurwitz). The obtained values of these generalized criteria are presented in Table 2. 
Table 2. Results of multicriteria optimization obtained by various methods of convolution of partial criteria

\begin{tabular}{|c|c|c|c|c|c|c|c|}
\hline $\begin{array}{c}\text { Convolution } \\
\text { methods for private } \\
\text { criteria }\end{array}$ & Generalized criterion & $\mathbf{u}_{\mathbf{1}}$ & $\mathbf{u}_{\mathbf{2}}$ & $\mathbf{u}_{\mathbf{3}}$ & $\mathbf{u}_{\mathbf{6}}$ & $\mathbf{u}^{*}$ & $\lambda_{k}\left(\mathbf{u}^{*}\right)$ \\
\hline Maximin criterion & $\mathbf{u}^{*}: \max _{\mathbf{u} \in U} \min _{k} \lambda_{k}(\mathbf{u})$ & 0.13 & 0.50 & 0.00 & 0.29 & $\mathbf{u}_{\mathbf{2}}$ & 0.50 \\
\hline $\begin{array}{c}\text { Minimax regret } \\
\text { criterion }\end{array}$ & $\begin{array}{c}\mathbf{u}^{*}: \min _{\mathbf{u} \in U} \max _{k} R_{k}(\mathbf{u}), \\
R_{k}(\mathbf{u})=\max _{\mathbf{u} \in U} \lambda_{k}(\mathbf{u})-\lambda_{k}(\mathbf{u})\end{array}$ & 0,87 & 0,39 & 0,80 & 0,71 & $\mathbf{u}_{\mathbf{2}}$ & 0.39 \\
\hline $\begin{array}{c}\text { Pessimism-optimism } \\
\text { criterion }(\gamma=0.4)\end{array}$ & \begin{tabular}{c}
$\mathbf{u}^{*}: \max _{\mathbf{u} \in U}\left[(1-\gamma) \min _{k} \lambda_{k}(\mathbf{u})+\gamma \max _{k} \lambda_{k}(\mathbf{u})\right]$ \\
\hline
\end{tabular} & 0.41 & 0.80 & 0.42 & 0.72 & $\mathbf{u}_{2}$ & 0.8 \\
\hline
\end{tabular}

The maximin rule is conservative because it focuses on the 'worst' value of an uncertain factor and is applicable when the 'failure' of the operation is highly undesirable, no matter what the best outcomes may be. According to the maximin criterion, the optimal strategy is $\mathbf{u}_{2}=(500 ; 300)$.

The Savage criterion is based on minimizing losses (regrets) $R_{k}(\mathbf{u})$ and is applicable in cases where the decision maker is not indifferent to the amount of possible gain. Among the evaluated alternatives, $\mathbf{u}_{2}$ entails the least regrets regarding the achieved values of the criteria.

The assessment of alternatives according to the Hurwitz criterion was carried out with a moderately pessimistic attitude of the decision maker to risk (which is expressed in terms of $\gamma=0.4$ ), thus for $\mathbf{u}_{2}$ the positive assessments according to the PC criterion (efficiency) were 'strengthened' and the negative ones according to the $\mathrm{C}$ criterion (economy) were 'smoothed'. Let us analyze stability of the solution according to Hurwitz when $\gamma$ changes in the interval $[0 ; 1]$. Figure 2 shows that for $\gamma \in[0 ; 0.55]$ the optimal strategy is $\mathbf{u}_{2}=(500$; $300)$, and for $\gamma \in(0.55 ; 1]$ the optimal strategy is $\mathbf{u}_{3}=(1000 ; 300)$.

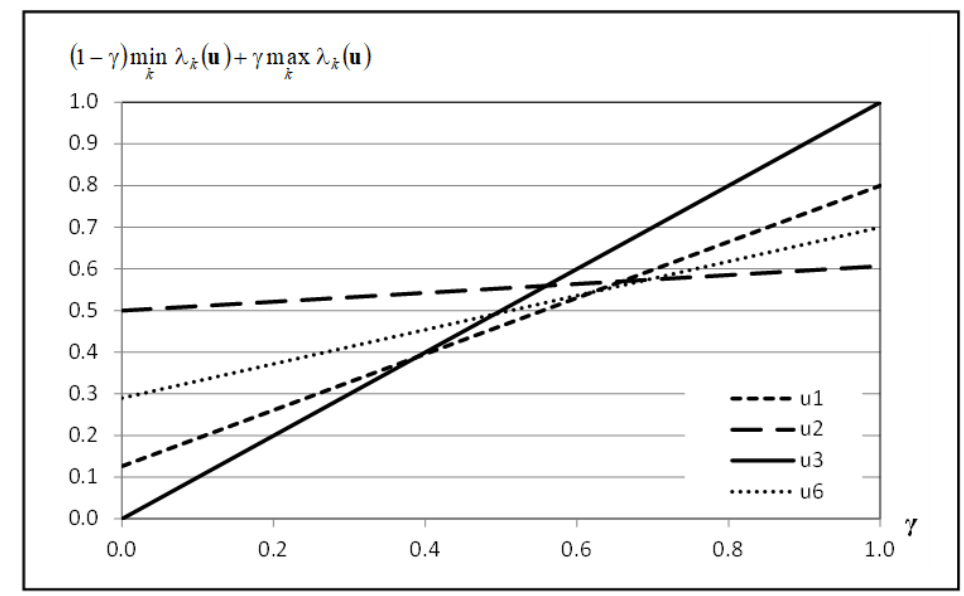

Fig. 2. Stability of the solution according to Hurwitz.

Thus, the generalized criteria determine priority of the solution $\mathbf{u}_{2}=(500 ; 300)$ over the rest of Pareto optimal solutions. In accordance with the priority decision $\mathbf{u}_{2}$, one-time investments in the amount of 800 thousand rubles ensure an increase in the production capacity of the site by $51.9 \mathrm{pp}$, while ensuring the necessary supply of PC and the balance of its elements. Such a solution represents the best (with the given formulation of the 
problem of preferences of the decision maker) ratio between the required target result and the cost of achieving it.

\section{Conclusion}

The developed economic and mathematical model of production capacity makes it possible to plan it based on the main technical and economic parameters of the production system control of $\mathrm{S}_{0}$ level, as well as to find the optimal solution from the standpoint of interval uncertainty. Optimization in this case is carried out on basis of two particular criteria maximizing potential productivity and minimizing the volume of one-time investments using classical methods of convolution of the vector of particular criteria. These methods for obtaining a generalized optimization criterion allow the decision maker's preferences to be included in the model; at the same time, it is necessary to take into account general methodological complexity of substantiating decisions, which is associated not so much with the difficulties of calculations as with the conceptual validity of the choice of the 'best' decision [14]. The proposed approach can be applied in operational management in the system of strategic development of production systems in industry.

The article was prepared in accordance with the Program of Fundamental Scientific Research of the State Academies of Sciences and the research plan of the Institute of Economics of the Ural Branch of the Russian Academy of Sciences for 2021-2023 on the topic: 'Methodology of innovative development of region-oriented systems in an unstable economic environment' (No. 0327-20210009).

\section{References}

1. Drucker, P.F. (1986) Management: Tasks, Responsibilities Practices. New York, Truman Talley Books. 554 p.

2. De Jesus Pacheco, D. A., Von Gilsa, C., Lacerda, D. P., Júnior, J. A. V. A., \& Goldmeyer, D. B. (2013). The proposition of a model of management in manufacturing capacity. [A proposição de um modelo de gestão da capacidade na manufatura] Espacios, 34(3)

3. Kim, J. S., \& Arnold, P. (1996). Operationalizing manufacturing strategy: An exploratory study of constructs and linkage. International Journal of Operations and Production Management, 16(12), 45-73. doi:10.1108/01443579610151751

4. Altendorfer, K., \& Minner, S. (2015). Influence of order acceptance policies on optimal capacity investment with stochastic customer required lead times. European Journal of Operational Research, 243(2), 555-565. doi:10.1016/j.ejor.2014.12.003

5. Pibernik, R., \& Yadav, P. (2008). Dynamic capacity reservation and due date quoting in a make-to-order system. Naval Research Logistics, 55(7), 593-611. doi:10.1002/nav.20304

6. Rafiei, H., \& Rabbani, M. (2012). Capacity coordination in hybrid make-tostock/make-to-order production environments. International Journal of Production Research, 50(3), 773-789. doi:10.1080/00207543.2010.543174

7. Martinez-Olvera, C. (2010). Impact of the alignment between the strategic and operational levels of a manufacturing enterprise. International Journal of Production Research, 48(4), 1195-1215. doi:10.1080/00207540802534723 
8. Azevedo, A. L., \& Sousa, J. P. (2000). Order planning for networked make-to-order enterprises Đa case study. Journal of the Operational Research Society, 51(10), 11161127. doi:10.1057/palgrave.jors. 2600066

9. Chakravorty, S. S., \& Atwater, J. B. (2006). Bottleneck management: Theory and practice. Production Planning and Control, 17(5), 441-447. doi:10.1080/09537280600682752

10. Gupta S., Star V. Production and Operations Management Systems. Taylor\&Francis group, 2014.

11. Lebedinskij I.L. Osnovnye proizvodstvennye fondy promyshlennosti [Basic production assets of the industry]. Lenizdat. 1979. (in Russ.).

12. Tenenev V.A. Reshenie zadachi mnogokriterial'noj optimizacii geneticheskimi algoritmami [Solving the problem of multicriteria optimization by genetic algorithms]. Intellektual'nye sistemy v proizvodstve. 2006. No. 2 (8). Pp. 103-109. (in Russ.).

13. Zak YU.A. Prikladnye zadachi mnogokriterial'noj optimizacii [Applied Problems of Multicriteria Optimization]. Moscow: Ekonomika, 2014. 455 p. (in Russ.).

14. Effektivnost' tekhnicheskih sistem [Reliability and efficiency in engineering, Vol. 3: The effectiveness of technical systems]. Moscow: Mashinostroenie Publ., 1988. 328 p. (in Russ.). 